\title{
Intra-operative diagnosis of an adult ureterocele complicated by hydronephrosis: a case report
}

\section{Alper Ileri, Zeynep Yasemin Onur, Dogay Nurtac Ozmus*, Irmak Atci Dogdu, Adnan Budak, Duygu Cebecik Ozmus, Pınar Tugce Baris, Yasam Kemal Akpak}

Department of Obstetrics and Gynaecology, Tepecik Training and Research Hospital, Izmir, Turkey

Received: 29 October 2020

Accepted: 09 December 2020

\section{*Correspondence:}

Dr. Dogay N. Ozmus,

E-mail: dogay.ozmus@hotmail.com

Copyright: ( $)$ the author(s), publisher and licensee Medip Academy. This is an open-access article distributed under the terms of the Creative Commons Attribution Non-Commercial License, which permits unrestricted non-commercial use, distribution, and reproduction in any medium, provided the original work is properly cited.

\begin{abstract}
Ureterocele is a cystic dilatation of the terminal ureter. Hydronephrosis is less commonly reported in individuals with ureterocele. We report a unique case of an incidental ureterocele with hydronephrosis in a 47-year-old woman; diagnosed with intraoperative control cystoscopy while performing total laparoscopic hysterectomy and bilateral salpingo- oophorectomy.
\end{abstract}

Keywords: Ureterocele, Laparoscopy, Cystoscopy, Urinary Abnormalities, Bladder abnormalities

\section{INTRODUCTION}

Ureterocele is a cystic dilatation of the terminal ureter within the bladder and/or the urethra. It may be diagnosed as an incidental finding on antenatal ultrasonography, or postnatally because of symptoms due to urinary tract infection (UTI) or obstruction. ${ }^{1}$ Presentation in an adult could be either by flank/back pain and recurrent UTI, or asymptomatic hydronephrosis detected incidentally. ${ }^{2}$

Incidence of ureterocele has been reported about $1 / 5000$ to $1 / 5000$ to $1 / 12000 .{ }^{1}$ Ureteroceles are classified as ectopic (a portion extends beyond the bladder neck into the urethra) or intravesical (entirely within the bladder). ${ }^{3}$

While many ureteroceles are detected on antenatal ultrasonography examination, some cases may present with an abdominal or vaginal mass, urinary incontinence. ${ }^{4}$ However few patients, may be diagnosed incidentally during imaging for other conditions. Adult ureteroceles are intravesically located and the obstruction is less severe. ${ }^{2}$ Clinic features in an adult could be either by flank/back pain, recurrent urinary tract infection or asymptomatic hydronephrosis found incidentally. ${ }^{2}$
We are reporting a case with incidental ureterocele was found intraoperative control cystoscopy while performing a total laparoscopic hysterectomy (TLH) and bilateral salpingo-oophorectomy (BSO) due to heavy menstrual bleeding and myoma uteri.

\section{CASE REPORT}

A 47-year-old woman with a complaining of heavy menstrual bleeding was admitted. The patient had gravida 3 and parity 3 with normal spontaneous vaginal delivery. No prior abdominal surgery was reported.

Preoperative hemoglobin was $9.8 \mathrm{gr} / \mathrm{dl}$, white blood cell was $4200 / \mathrm{ml}$, platelet was $247 \times 10^{3} / \mathrm{ml}$, urea: $25 \mathrm{mg} / \mathrm{dl}$, creatine: $0,9 \mathrm{mg} / \mathrm{dl}$ and coagulation parameters were normal. A specific gravity was 1023, ph was 5.0; no cellular elements, no protein, and nitrite, negative urobilinogen, bilirubin and ketone were found in urine analysis.

Uterus measuring $8 \times 5.6 \times 5.7 \mathrm{~cm}$, endometrial thickness $4 \mathrm{~mm}$ and intramural leiomyoma measuring $2.7 \times 2.5 \mathrm{~cm}$ which was distorting endometrium, were found in transvaginal ultrasonography examination. 
TLH, and BSO were performed. Cystoscopy was implemented at the end of the surgery. An exophytic lesion was found neighboring the right ureteral orifice (Figure 1).

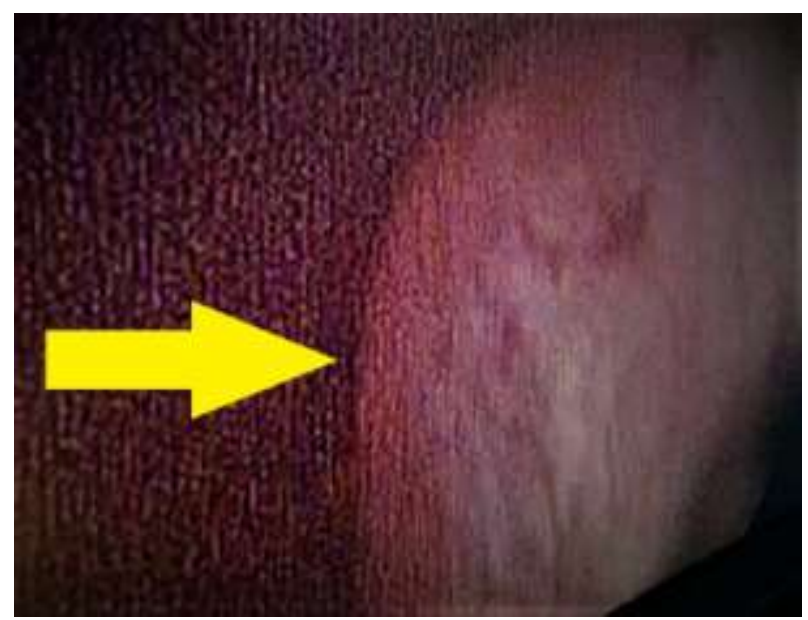

Figure 1: Intraoperative ureterocele image of the cystoscopy.

The case was consulted to urology intraoperatively. Ureterocele neighboring right ureter orifice, measuring $8 \times 5 \times 3 \mathrm{~cm}$ was found in ultrasonography. Also, the examination suggested right renal hydronephrosis and chronic renal and bladder dysfunction. Urographic computed tomography (CT) has been planned. Postoperative CT showed right pelvicaliectasis (Figure 2).

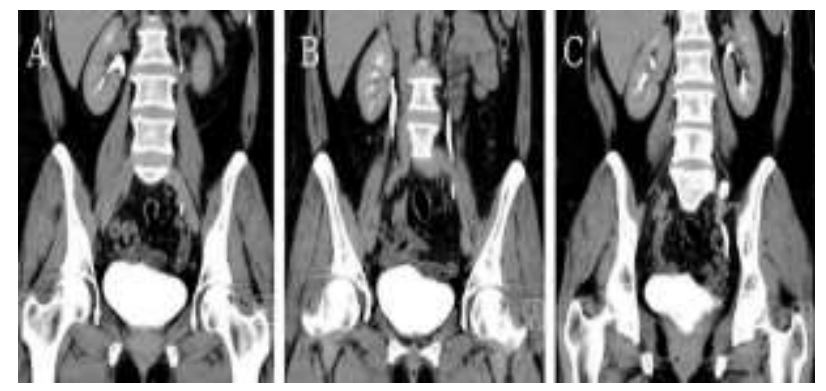

Figure 2: 3D CT urography (A) Pelvicaliectasis of the right kidney (B) hydroureteronephrosis of the right ureter (C) an irregular appearance on the right side of the baldder due to ureterocele.

Intravenous pyelogram (IVP) was suggested since CT could not detect ureterocele. On the IVP images, characteristic cobra head sign of ureterocele was observed (Figure 3). No postoperative complication was occurred. No pathological findings were present in abdomen and renal physical examination before discharge. Control urology appointment was planned.

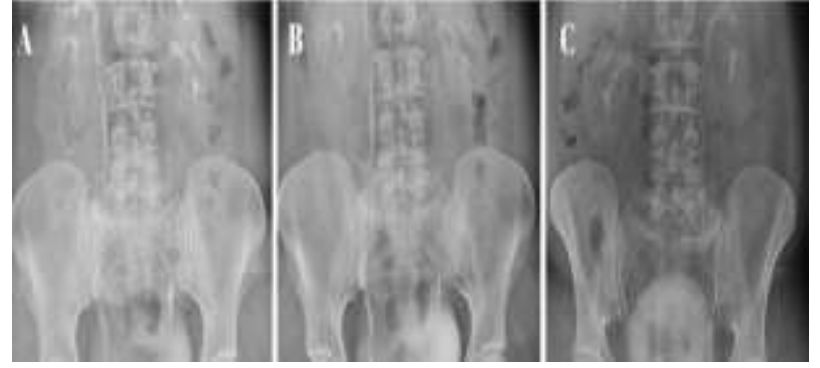

Figure 3: Intravenous pyelography (IVP) (A) fifteenth (15') minute of IVP (B) forty-fifth (45') minute of IVP (C) sixtieth (60') minute of IVP.

There was no need for an ethical approval because of since this was just a case report and patient's confidentiality were assured. Written informed consent was obtained from the patient for publication of this case report and accompanying images.

\section{DISCUSSION}

Ureteroceles have diverse presentations ranging from sepsis, recurrent UTIs, renal failure, to no symptoms at all being detected incidentally or by antenatal ultrasonography. ${ }^{5}$ Currently, most of the ureteroceles are diagnosed in the screening for congenital malformations. ${ }^{6}$ The most common postnatal presentation is during an evaluation for UTI in early infancy. ${ }^{4} 10-20 \%$, however, exist as simple ureteroceles and cause no symptoms. ${ }^{7}$ Most ureteroceles are related to a single system in adults. The stasis at the ureteral meatus due to the partial obstruction of the ureterocele may induce stone formation, causing renal colic and/or UTI. ${ }^{2}$ Also Vasu et al reported a patient with a progressed disease to renal failure due to bilateral ureterocele. ${ }^{8}$ In our case we observed an incidental ureterocele complicated with hydronephrosis the control cystoscopy after TLH and BSO which is unusual as ureterocele causing obstruction in adults and also less commonly reported. ${ }^{9}$

Contrast imaging of the ureters may be useful in the patients with known or suspected urinary tract anomalies. Preoperative imaging with computed tomography urography can be beneficial in demonstrating structural abnormalities in the urinary tract. ${ }^{10}$ Still Aslaksen et al recommended that the preoperative urography should be replaced by the preoperative ultrasonography when a screening of the upper urinary tract is necessary prior to hysterectomy. ${ }^{11}$ This minimal invasive approach could be implemented into preoperation procedures of the hysterectomy.

Urinary tract injury in laparoscopic hysterectomy have been reported to range from 1.2 to 2.6 percent. ${ }^{12}$ Visual inspection of the urinary tract is routinely performed during gynecologic surgery. In addition, cystoscopy can be performed routinely for all or selectively. In our clinic we perform cystoscopy routinely in total laparoscopic hysterectomy. Cystoscopy is associated with a higher 
detection rate of the urinary tract injuries compared to visualization alone, especially for ureteral injuries. In a systematic review and meta-analysis, nearly twice as many ureteral injuries were detected with routine use of cystoscopy than without. ${ }^{13}$ However, there is no consensus for the routine use of the intraoperative cystoscopy to screen for urinary tract injury in women undergoing major gynecologic surgery. ${ }^{14}$ Surgeons are encouraged to perform cystoscopy at the time of hysterectomy, but the decision to do so is surgeondependent. ${ }^{15,16}$ In another case report published in Turkey, Kilinc and Akpak emphasized the benefits of cystoscopy with gynecological operations particularly with regard to notice of bladder injury. ${ }^{17}$ Consisting with recent suggestions, we performed cystoscopy intraoperatively in our patient. This preventive approach of our clinic, obtained ureterocele diagnosis and ensured patient's hydronephrosis was not a surgery complication afterwards due to supposed urinary tract injury. Furthermore, gynecologic surgeons should collaborate with urologists to address urogenital injuries, and focus on multidisciplinary and minimally invasive approaches intraoperatively likewise in our case.

\section{CONCLUSION}

Ureterocele represent a clinical challenge cosidering diagnosis due to variable presentations in adults. To the best of our knowledge this is this is a rare case of an adult woman having ureterocele with hydronephrosis in advanced age. Considering potential benefits; performing preoperative urinary tract ultrasonography and cystoscopy during TLH could be essential for gynecologic surgeons.

\section{Funding: No funding sources Conflict of interest: None declared \\ Ethical approval: Not required}

\section{REFERENCES}

1. Sander JC, Bilgutay AN, Stanasel I, et al. Outcomes of endoscopic incision for the treatment of ureterocele in children at a single institution. J Urol. 2015; 193(2): 662-6.

2. Halachmi S, Pillar G. Congenital urological anomalies diagnosed in adulthood - Management considerations. J Pediatr Urol. 2008;4(1):2-7.

3. Glassberg KI, Braren V, Duckett JW. Suggested terminology for duplex systems, ectopic ureters and ureteroceles. J Urol. 1984;132(6):1153-54.

4. Coplen DE, Duckett JW. The Modern Approach to Ureteroceles. J Urol. 1995;153(1):166-71.
5. Atta ON, Alhawari HH, Murshidi MM, Tarawneh E, Murshidi MM. An adult ureterocele complicated by a large stone: A case report. Int J Surg Case Rep. 2018;44:166-71.

6. Merlini E, Lelli Chiesa P. Obstructive ureterocele An ongoing challenge. World J Urol. 2004;22(2):107-14.

7. Conlin MJ, Skoog SJ, Tank ES. Current management of ureteroceles. Urology. 1995;45(3):357-62.

8. Vasu TS, Clayton W, Elliot RSHL. Bilateral ureteroceles progressing to reversible acute renal failure in an adult. Can J Urol. 2006;13(1):2993-6.

9. Aeron R, Sokhal AK, Kumar M, Sankhwar S. Giant hydronephrosis in a case of ureterocele with duplex system: an entity yet not reported. Bio Med J Case Rep. 2017;2017:1-3.

10. Findley AD, Solnik MJ. Prevention and management of urologic injury during gynecologic laparoscopy. Curr Opin Obstet Gynecol. 2016;28(4):323-28.

11. Aslaksen A, Göthlin JH, Geitung JT, Anker C. Ultrasonography Versus Urography as Preoperative Investigation Prior to Hysterectomy. Acta Obstet Gynecol Scand. 1989;68(5):443-5.

12. Wong JMK, Bortoletto P, Tolentino J, Jung MJ, Milad MP. Urinary tract injury in gynecologic laparoscopy for benign indication: A systematic review. Obstet Gynecol. 2018;131(1):100-8.

13. Teeluckdharry B, Gilmour D, Flowerdew G. Urinary tract injury at benign gynecologic surgery and the role of cystoscopy. Obstet Gynecol. 2015;126(6):1161-9.

14. Sandberg EM, Hehenkamp WJK, Geomini PM, Janssen PF, Jansen FW, Twijnstra ARH. Laparoscopic hysterectomy for benign indications: clinical practice guideline. Arch Gynecol Obstet. 2017 Sep;296(3):597-606.

15. Role T, Obstetrician G, Practice G. The Role of Cystourethroscopy in the Generalist Obstetrician Gynecologist. J Hosp Infect. 2007;110(372):221-24.

16. Article S. AAGL Practice Report: Practice Guidelines for Intraoperative Cystoscopy in Laparoscopic Hysterectomy. J Minim Invasive Gynecol. 2012;19(4):407-11.

17. Kilinc E, Akpak YK. A Rare Case of Unrecognized and Uncommon Bladder Perforation after Transobturator Tape Procedure. Case Rep Med. 2015;2015:731593.

Cite this article as: Ileri A, Onur ZY, Ozmus DN, Dogdu IA, Budak A, Ozmus DC, et al. Ureterocele in the woman that was performed total laparoscopic hysterectomy bilateral salpingooferectomy due to bening gyaecological reason. Int J Reprod Contracept Obstet Gynecol 2021;10:347-9. 